\title{
Article
}

\section{Victim empathy-based content in aggression treatment: Exploring impact within a secure forensic hospital}

Nally, Tom, Ireland, Jane Louise, Greenwood, Leah Charlotte, Ireland, Carol Ann and Birch, Philip

Available at http://clok.uclan.ac.uk/37597/

Nally, Tom, Ireland, Jane Louise ORCID: 0000-0002-5117-5930, Greenwood, Leah Charlotte, Ireland, Carol Ann ORCID: 0000-0001-7310-2903 and Birch, Philip (2021) Victim empathy-based content in aggression treatment:

Exploring impact within a secure forensic hospital. Journal of Forensic Practice . ISSN 2050-8794

It is advisable to refer to the publisher's version if you intend to cite from the work. http://dx.doi.org/10.1108/JFP-01-2021-0001

For more information about UCLan's research in this area go to

http://www.uclan.ac.uk/researchgroups/ and search for < name of research Group>.

For information about Research generally at UCLan please go to http://www.uclan.ac.uk/research/

All outputs in CLoK are protected by Intellectual Property Rights law, including Copyright law. Copyright, IPR and Moral Rights for the works on this site are retained by the individual authors and/or other copyright owners. Terms and conditions for use of this material are defined in the policies page.

\section{CLoK}

Central Lancashire online Knowledge www.clok.uclan.ac.uk

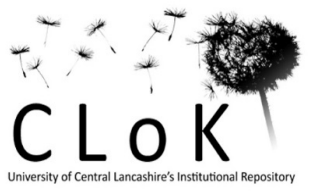


Victim empathy-based content in aggression treatment: Exploring impact within a secure forensic hospital

\begin{tabular}{|r|l|}
\hline Journal: & Journal of Forensic Practice \\
\hline Manuscript ID & JFP-01-2021-0001.R1 \\
\hline Manuscript Type: & Research Paper \\
\hline Keywords: & $\begin{array}{l}\text { Offender Treatment, Victim Empathy, Life Minus Violence, LMV-E, } \\
\text { Therapy, Trauma }\end{array}$ \\
\hline
\end{tabular}

SCHOLARONE $^{\text {TM }}$

Manuscripts 


\section{MANUSCRIPT DETAILS}

TITLE: Victim empathy-based content in aggression treatment: Exploring impact within a secure forensic hospital

\section{ABSTRACT:}

This study explores the impact of inclusion of victim empathy-based content in offender treatment.

It presents first a systematic review of 20 papers, before proceeding to consider a qualitative interviews with therapists $(n=7)$, and forensic patients $(n=5)$, who had completed a long-term violence therapy (Life Minus Violence â€" Enhanced, LMV-EÂC). The research explored perceptions of forensic patients and treatment facilitators when completing victim empathy work, and explored any negative effects this may have.

Findings from the systematic review indicated five themes: (1) Interventions incorporating victim empathy can be effective; (2) There are positive risk-understanding consequences from completing victim empathy work; (3) Offenders perceive victim empathy positively; (4) The emotional impact of victim empathy work on offendersâ $€^{\mathrm{TM}}$ is poorly explored and, (5) Completing victim empathy in treatment groups receives mixed evaluations from offenders. The systematic review was used to inform the interview themes for the resulting qualitative study with facilitators and forensic patients. This study indicated six themes: (1) Victim empathy content facilitates change; (2) Victim empathy content can be difficult for patients; (3) Victim empathy content can lead to an emotional response; (4) Victim empathy content can be beneficial, with the process important; (5) Victim empathy content can help understand risk, and (6) Patientsâ $€^{\mathrm{TM}}$ experience of treatment begins before attending sessions.

CUST_RESEARCH_LIMITATIONS/IMPLICATIONS_(LIMIT_100_WORDS) :No data available.

The potential impact of victim empathy content needs to be evaluated before sessions are completed, accounting for client expectations and treatment readiness. This should include ensuring that appropriate support is in place. Any support provided to patients should be regularly reviewed.

CUST_SOCIAL_IMPLICATIONS_(LIMIT_100_WORDS) :No data available.

The study represents the first to apply detailed analysis to this topic area and with a complex group. 


\section{RUNNING HEAD: VICTIM EMPATHY IN AGGRESSION TREATMENT}

Victim empathy-based content in aggression treatment: Exploring impact within a secure forensic hospital. 


\title{
RUNNING HEAD: VICTIM EMPATHY IN AGGRESSION TREATMENT
}

\begin{abstract}
This study explores the impact of inclusion of victim empathy-based content in offender treatment. It presents first a systematic review of 20 papers, before proceeding to consider a qualitative interviews with therapists $(n=7)$, and forensic patients $(n=5)$, who had completed a long-term violence therapy (Life Minus Violence - Enhanced, LMV-EC). The research explored perceptions of forensic patients and treatment facilitators when completing victim empathy work, and explored any negative effects this may have. Findings from the systematic review indicated five themes: (1) Interventions incorporating victim empathy can be effective; (2) There are positive risk-understanding consequences from completing victim empathy work; (3) Offenders perceive victim empathy positively; (4) The emotional impact of victim empathy work on offenders' is poorly explored and, (5) Completing victim empathy in treatment groups receives mixed evaluations from offenders. The systematic review was used to inform the interview themes for the resulting qualitative study with facilitators and forensic patients. This study indicated six themes: (1) Victim empathy content facilitates change; (2) Victim empathy content can be difficult for patients; (3) Victim empathy content can lead to an emotional response; (4) Victim empathy content can be beneficial, with the process important; (5) Victim empathy content can help understand risk, and (6) Patients' experience of treatment begins before attending sessions. The results are discussed with attention to similarity in perceptions and experiences between staff and patients, with suggestions made for clinical implications and future research.
\end{abstract}

Key words: Offender Treatment; Victim Empathy; Life Minus Violence; LMV; Violence; Therapy; Trauma. 


\section{RUNNING HEAD: VICTIM EMPATHY IN AGGRESSION TREATMENT}

\section{Victim empathy-based content in aggression treatment: Exploring impact within a secure forensic hospital.}

Empathy, while a contested term, is understood to involve an emotional response, dependent on trait and state influences, as well as a cognitive process, relating to an accurate perception and understanding of others' experiences (Cuff et al., 2016). There is agreement that empathy includes recognising other's emotional experiences, perspective taking, emotional experiences and behavioural responses (Hanson, 2003; Marshall et al., 1995; Pithers, 1994). This paper explores the concept of empathy used within violent offender treatment. Consequently, the term victim empathy is employed and refers to the extension of general empathy abilities to general or specific victim groups.

Empathy deficits may contribute to individuals' risk of engaging in offending behaviour. The Model of the Empathic Process (MEP; Barnett \& Mann, 2016) indicates that individuals follow pathways to generating empathic responses, via emotional contagion or cognitive appreciation. The model argues that individuals access emotional contagion immediately by either directly imagining the experience of observed individuals or imagining how they would feel in a similar situation, based on their internal beliefs and experiences. They could, alternatively, cognitively appraise a situation by these processes, where emotional contagion occurs simultaneously or after cognitive appraisal. Thus, individuals respond empathically through direct emotional experience or through cognitively driven emotional experiences. Offenders can have deficits in interpreting social cues and recognising others' distress (Archer \& Haigh, 1999; Gillespie et al., 2015; Hoaken et al., 2007; Polaschek et al., 2009; Robinson et al., 2012). As empathy may be related to violent and prosocial behaviours (Bock \& Hosser, 2014; Ding \& Lu, 2016; Jolliffe \& Farrington, 2004; Van Langen et al., 2014), specific treatment addressing empathy may be important (van Berkhout 


\section{RUNNING HEAD: VICTIM EMPATHY IN AGGRESSION TREATMENT}

\& Malouff, 2016). As offender treatment aims to increase offenders' understanding and skills, victim empathy has become a common inclusion in offence-focused interventions (Carich et al., 2004; Day et al., 2010; Webster et al., 2005).

Literature that explores victim empathy treatment indicates that it is positively appraised by offenders (Levenson et al., 2009; Levenson et al., 2010; Levenson et al., 2014). Levenson et al. (2009) explored the experiences of male sex offenders $(n=338)$, completing CBT-based group sex offender treatment. Ninety-four percent of participants rated accepting responsibility as very important to their treatment recovery, with $92 \%$ rating understanding the impact of sexual abuse on victims and others, as equally important. Approximately one fifth of the sample indicated that they would want to spend more time in treatment, covering accepting responsibility and victim empathy respectively. Indeed, the literature indicates that most offenders do not experience adverse or distressing consequences, beyond those expected in victim empathy intervention (Levenson et al., 2009; Levenson et al., 2010; Zosky, 2018), but the emotional impact is yet to be explored.

A useful theory to apply within this context is Social Identity and Categorization Theory (SIT; Tajfel, 1978; Turner et al., 1979; Tajfel \& Forgas, 2000), aiding an understanding why victim empathy-based content could be distressing. Individuals align themselves to groups, who provide them with a sense of belonging and pride. They may identify themselves with a positively appraised group, or reappraise qualities they have to fit socially desirable groups, to minimise their own negative behaviours and maintain a moral identity, which accepts their offending behaviour challenges. Indeed, individuals who engage in offending behaviours can create positive self-identities through resisting stigmatising labels and attributions placed upon them, consistent with their need to maintain a positive self-esteem and self-identity (Geiger \& Fischer, 2005; Ward, 2002; Ward \& Mann. 2004). Consequently, offenders may conceal more negative self-identities from others, to protect 


\section{RUNNING HEAD: VICTIM EMPATHY IN AGGRESSION TREATMENT}

themselves from potential adverse effects on their emotional well-being and guard against the negative perceptions of others (Quinn \& Earnshaw, 2013). Revealing hidden self-identities can be distressing and are thus worthy of attention, as engaging in victim empathy work can be confronting for offenders, who may experience distress as a result (Quinn \& Chaudoir, 2009).

Offenders' response to victim empathy content may also be explained using the Perception-Action Model of Empathy (Preston, 2007). The model proposes that individuals' experience of empathy is shared between the observer and the individual that is distressed, with the observation of distress leading to an automatic empathic response (Preston, 2007). Victim empathy content can include methods that encourage offenders to observe and reflect on the emotional impact of their or others' offending (Ireland et al., 2009; Mann \& Barnett, 2013). Consequently, offenders may experience distress due to the observation, or presentation, of distress in others during treatment. Shame is also a common response observed in offenders during treatment, which can be a threat to the maintenance of a moral identity (Woodyatt \& Wenzel, 2014). Offenders can self-stigmatise, accepting criminal stigmatising labels assigned by others, such as being labelled an 'offender' (Moore et al., 2016; Moore et al., 2018). A consequence of such may result in a poor sense of belonging and further reluctance by offenders to disclose/discuss their identity, especially in psychiatric settings (Newheiser \& Barreto, 2014; West et al., 2015).

The current study aimed to explore perceptions of patients and facilitators, in a secure forensic hospital, of victim empathy-based content in therapy delivery. Additionally, it aimed to explore the impact of victim empathy-based content on the wellbeing of both treatment facilitators and offenders. A systematic review was undertaken first, followed by a qualitative interview study with staff and patients, which drew on the themes identified in the systematic review. The research was underpinned by the following questions: 


\section{RUNNING HEAD: VICTIM EMPATHY IN AGGRESSION TREATMENT}

1. What are the perceptions of offenders completing victim empathy-based content?

2. What are the perceptions of facilitators delivering victim empathy-based content?

3. What are the effects of completing victim empathy-based content?

\section{Systematic Review: Exploring Victim Empathy Content in Offender Treatment Programs.}

\section{Method}

\section{Procedure}

A systematic review of the literature was undertaken to identify the impact of empathy content on psychological functioning and aggression. This followed PRISMA guidelines. Search terms were 'Victim OR Offence AND Empathy OR Consequences AND Effects OR Impact OR Results AND Psychiatric OR Offender OR Patient OR Prisoner'1. Two hundred and twenty-nine papers were initially identified, with a review of abstracts reducing this to 20 (see * in reference list). Thematic Analysis was employed to determine, analyse and report themes (patterns) within the data using the process identified by Braun \& Clarke (2012). A coding scheme was developed to capture patterns in the data, with the qualitative analysis program, NVivo, used to generate codes. The data was explored and reviewed on multiple occasions, allowing for common themes to be identified. Inter-rater reliability was conducted on $10 \%$ of the dataset, demonstrating good evidence of reliability.

\section{Results}

Five themes were identified: (1) Interventions incorporating victim empathy can be effective; (2) Positive risk-understanding consequences from completing victim empathy work; (3) Offenders perceive victim empathy positively; (4) The emotional impact of victim empathy

\footnotetext{
${ }^{1}$ Databases that were searched included PsychInfo, PsychArticles, Criminal Justice Abstracts and SocINDEX
} 


\section{RUNNING HEAD: VICTIM EMPATHY IN AGGRESSION TREATMENT}

work on offenders' is poorly explored; (5) Completing victim empathy in treatment groups receives mixed evaluations from offenders. Next is an illustration of each theme.

\section{Theme one - Interventions incorporating victim empathy can be effective}

Most studies included explored treatment incorporating various modules and content, in addition to victim empathy. Only four papers focused exclusively on victim empathy content or treatment. The remaining papers reviewed interventions that included victim empathy work but did not connect this with specific outcomes. Thus, the direct relationship between completing victim empathy work and outcomes was not made. This theme comprised two subthemes, as follows:

$\underline{\text { Subtheme one - Interventions that have victim empathy aspects report reductions in }}$ offending attitudes: Five studies explored the impact of victim empathy content on cognition (Bairn et al., 1999; Foubert, 2000; O’Donohue et al., 2003; Stephens \& George, 2009; Wakeling et al., 2013). Stephens and George (2009) examined the impact of a rape prevention intervention with male college students $(n=137)$, finding that the use of victim empathy, using video material, resulted in decreased rape myth acceptance during a fiveweek follow up period. However, this was not effective for individuals classed as 'high risk' of rape. Similar findings were reported by O’Donohue et al. (2003) and Foubert (2000). However, Bairn et al. (1999) explored the use of psychodrama, which aimed to increase victim empathy in a group of male sexual offenders $(n=9)$.

$\underline{\text { Subtheme two - Interventions that have victim empathy aspects report positive }}$ impacts on criminogenic factors: Seven studies explored the impact of victim empathy content on other criminogenic factors, including empathy ability and awareness of their behaviour (Bairn et al., 1999; Marshall et al., 1996; O’Donohue et al., 2003; Schewe \& O'Donohue, 1993; Stephens \& George, 2009; Wakeling et al., 2013; Zosky, 2018). Stephens and George (2009) examined a rape prevention intervention with male college students 


\section{RUNNING HEAD: VICTIM EMPATHY IN AGGRESSION TREATMENT}

$(n=137)$. They found that inclusion of victim empathy increased participant's empathy towards victims, sustained over the five-week follow up period. Schewe and O'Donohue (1993) evaluated the use of two rape prevention interventions in 'high risk' men $(n=68)$; one designed to increase victim empathy, the other to decrease rape myth acceptance. The findings indicated that the empathy treatment increased participants' victim empathy ratings and decreased rape myth acceptance more than the no treatment or rape myth groups.

\section{Theme two - There are positive risk-understanding consequences from completing victim} empathy work

Three studies explored offenders' perceptions of change following completion of victim empathy work (Levenson et al., 2009; Levenson et al., 2010; Schewe \& O'Donohue, 1993). Levenson et al. (2009) found that, in sexual offenders in treatment $(n=338)$, over $80 \%$ stated that they learned more about their past offending and about preventing future offending. Schewe and O'Donohue (1993) evaluated the credibility of two interventions designed to reduce risk of rape perpetration, one designed to increase empathy and one designed to reduce rape myth acceptance $(n=68)$. Participants that completed the interventions felt both interventions were helpful in reducing their future risk of rape perpetration.

\section{Theme three - Offenders perceive victim empathy favourably}

Five studies explored the perceptions of clients who have completed victim empathy content (Colton et al., 2009; Levenson et al., 2009; Levenson et al., 2010; Schewe \& O'Donohue, 1993; Zosky, 2018). Studies that explored offenders' perception of victim empathy work received positive evaluations. For instance, Levenson et al. (2009), in a sample of male sexual offenders $(n=338)$, found that $94 \%$ and $92 \%$ of the sample, respectively, found accepting responsibility and understanding the impact of their offending to be important to them. In addition, $80 \%$ of the sample stated that they were satisfied with their treatment and 


\section{RUNNING HEAD: VICTIM EMPATHY IN AGGRESSION TREATMENT}

felt that this had been helpful for them. Levenson et al. (2010) also found a significant positive correlation between offenders' perceived importance and satisfaction. Furthermore, Colton et al. (2009) found, in a smaller sample of sexual offenders $(n=33)$, that $57 \%$ felt victim empathy work was helpful in increasing their knowledge and awareness of victim impacts.

\section{Theme four - The emotional impact of victim empathy work on offenders' is poorly explored}

One study explored offenders' perceptions of attending victim impact panels (Zosky $2018, \mathrm{n}=340$ ), with this focusing on intimate partner violence. Here, only five percent of offenders reported that hearing victim accounts led to the triggering of prior traumatic experiences. Participant comments related to recounting experiences of exposure to violence in childhood. The researchers suggested that the trauma trigger did not relate to the victims' experience but to memories of their own abuse. Offenders also described emotions, such as empathy, remorse and sadness, which they felt were appropriate. However, there was no further attention to emotional impacts in the literature, which highlights the paucity of attention to such reactions.

\section{Theme five - Completing victim empathy in treatment groups receives mixed evaluations from offenders}

Five studies explored the mode of treatment in relation to victim empathy content (Colton et al., 2009; Day, 1999; Levenson et al., 2009; Levenson et al., 2010; Pithers, 1994). However, findings were mixed regarding whether this should be completed in a group or individually. Levenson et al. (2009) found that $90 \%$ of their sample felt sharing their offending experience with other offenders, including being confronted in a group, was important to them. However, $31 \%$ also felt that they would rather have attended individual rather than group treatment. Colton et al. (2009) explored offenders' $(n=35)$ perceptions of a 
Sexual Offender Treatment Program (SOTP) and found that offenders preferred not to be in groups with 'high risk' sexual offenders, did not want to hear about the problems these individuals had, with group sessions creating emotions such as anger, confusion and a loss of hope.

\section{Qualitative Study of Experiences: Exploring Patient and Treatment Facilitator Experience of Completing Victim Empathy Content in a Secure Forensic Hospital}

\section{Method}

\section{Participants}

Treatment facilitators $(n=7)$ and patients $(n=5)$ who had completed either group $(n=3)$ or individual $(n=2)$ aggression treatment took part. The facilitator sample (male, $n=3$ and female, $n=4)$ held various roles; namely, trainee forensic psychologists $(n=4)$, forensic treatment facilitator $(n=1)$ and nurse therapists $(n=2)$. All facilitators had facilitated the offence focused treatment in its entirety, and most had completed both group and individual treatment $(n=6)$. The patient sample was all male and had completed a long-term aggression focused treatment - Life Minus Violence - Enhanced (Ireland et al., 2009). This is a Cognitive Behaviour Therapy (CBT) based, multi-module long-term treatment program. It has a dedicated module that focuses on victim empathy and consequences.

\section{Interview schedule}

An interview aide-memoire was developed, informed by the systematic review. The interviews employed here aimed to explore with participants their understanding, perceptions and experiences of victim empathy-based treatment. 


\section{RUNNING HEAD: VICTIM EMPATHY IN AGGRESSION TREATMENT}

\section{Procedure}

The study formed part of an approved service evaluation for the participating NHS organisation. Informed consent was gathered from all participants. All were provided with an information sheet outlining the service evaluation and debrief information. Participants completed interviews. Each interview ranged from 30 to 60 minutes. Participant responses were transcribed.

\section{Analysis}

Thematic Analysis was employed (Braun \& Clarke, 2012). Each transcribed interview was read thoroughly before the coding process was started and then coded using a qualitative data coding program ${ }^{2}$. A deductive coding strategy was developed, focusing on participants understanding of victim empathy-based treatment, affective responses and perceived benefits or limitations (Braun \& Clarke, 2012). Inductive coding was employed, in response to meaningful information in the interview data, such as the delivery of the intervention and participants expectations of the intervention. Each interview was given a label to allow for anonymity (Facilitator Participant $=$ F1; Patient Participant $-\mathrm{P} 1)$.

\section{Results}

Overall, six themes were identified. There were four shared themes between facilitator and patient participants. These included: (1) Victim empathy content facilitates change; (2) Victim empathy content can be difficult for patients; (3) Victim empathy content can lead to an emotional response; (4) Victim empathy content can be beneficial, with the process important. One theme was identified as unique to facilitator participants, namely 'victim empathy content helps understand risk'. One theme was identified as unique to patient

${ }^{2}$ NVivo (QSR International) 


\section{RUNNING HEAD: VICTIM EMPATHY IN AGGRESSION TREATMENT}

participants, 'patients' experience of treatment begins before attending sessions'. Each theme is illustrated next, commencing with the shared themes.

\section{Shared Themes}

\section{Theme one - Victim empathy content facilitates change}

Both patients and facilitators described behavioural or cognitive changes after completing victim empathy content. There was mutual understanding that this content could provide skills and learning that is conducive to reducing levels of violence after treatment. Four subthemes emerged from the analysis, as illustrated next.

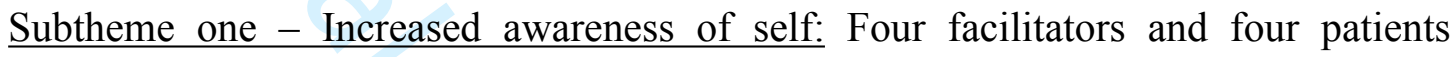
described victim empathy content as an effective facilitator of learning. This included patients learning about their own risks and cognitions and the need to change their behaviours, e.g.:"[it] helped identify triggers for their harmful...behaviour, whereas they couldn't before" (F2) and "[victim empathy-based content] helped me to understand my emotions and the situations before [offence] happened" (P4). This also involved three patients considering their offences in new ways or with a different perspective, e.g.: "I found that I had not thought about how many people I affect” (P6).

Subtheme two - Increased awareness of others: Four facilitators and three patients described patient development following their engagement in victim empathy-based treatment. They perceived their ability to consider other's feelings to increase, e.g.: "Before the client focused on self-impact... after they talked more about other's-impact" (F2) and "I sympathised with [the victim] after learning about the consequences of what I did" (P1).

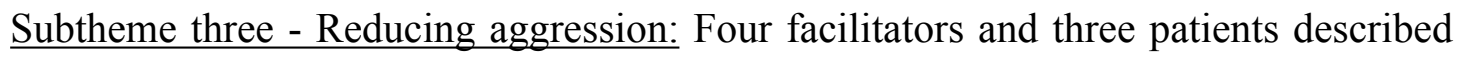
victim empathy-based treatment as helpful to the goal of reducing future aggression, through increased recognition of empathy and victim consequences, e.g.: "[victim empathy-based treatment] is helpful to reduce proactive... and reactive aggression.... They start to recognise 


\section{RUNNING HEAD: VICTIM EMPATHY IN AGGRESSION TREATMENT}

empathy as an important skill in reducing aggression" (F5) and "I leaned to be assertive but not aggressive...its ok to be angry but I don't let it turn to aggression” (P2).

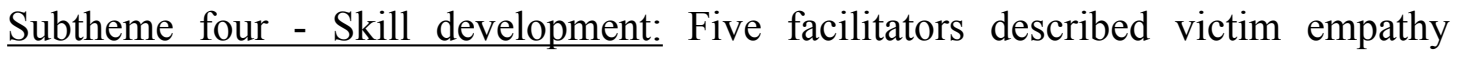
content as an effective facilitator of skill development, particularly for cognitive skills such as perspective taking and consequential thinking, and cognitive empathy, e.g.: "they can understand when they do something, what it will cause, such as consequences for self and others" (F5). However, while one facilitator noted the importance of developing skills through skills practices, another felt patients were not always able to use them outside of the treatment setting; "I don't think they [patients] apply the skills that well” (F1).

\section{Theme two - Victim empathy content can be difficult for patients}

Victim empathy content was recognised as difficult for patients to complete. Three facilitators and two patients described this to involve skills patients may already have a deficit in, which can lead to them experiencing difficulties in completing treatment. This included, for instance, difficulties with perspective taking and consequential thinking, e.g.: "some [patients] can't see past the immediate consequences" (F2) and "[Victim empathybased treatment] is good but depends on insight so it has limits. Also depends on their acceptance of behaviours" (F6). Indeed, one patient found the reflective nature of victim empathy content to be difficult to process, causing negative feelings: "it upset me really, I felt as though I was dragging up painful memories of the past. We also did a scenario, which was painful....it reminded me of everything I didn't want to be reminded of', (P4).

\section{Theme three - Victim empathy content can lead to an emotional response}

Five facilitators and four patients referred to victim empathy-based treatment leading to an emotional response in patients. Five subthemes were identified and illustrated next.

$\underline{\text { Subtheme one - Patients experienced a range of emotions: Four facilitators described }}$ observing emotional responses in patients, while completing victim empathy content. This 


\section{RUNNING HEAD: VICTIM EMPATHY IN AGGRESSION TREATMENT}

was also highlighted by three patients. Negative emotions appeared to result from the focus on the victim of the offence and recollection of memories associated with their offences, which could negatively impact their treatment engagement, e.g.: "one patient got annoyed for focusing too much on the victim" (F5), and "where the clients showed more anxiety, it could have inhibited responses" (F4). A patient commented on how; "I felt feelings I haven't felt in a long time, like sadness" (P4).

Subtheme two - Reluctance to complete victim empathy work: Three facilitators described some apprehension and reluctance when discussing victim empathy content, both from facilitators delivering this and patient reactions to content. For instance, one considered a patient's perspective, reporting how, "they [patients] think it is worse than it is" (F5). However, facilitators also described feeling apprehensive about delivering victim empathybased content: "I considered 'just doing enough' and stopping when module goals are met" (F2).

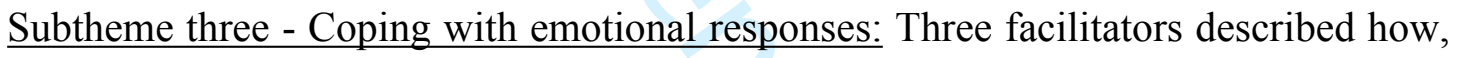
whilst some participants described being emotionally affected, this was managed effectively and did not have a lasting effect, with a need for additional emotional support recognised for some e.g.: "[they] are not overly distressed ...they manage it well" (F7) and "some [patients] require more emotional support...they don't have as good coping strategies" (F5).

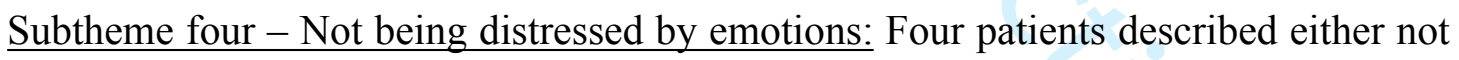
being emotionally affected, or feeling that their responses were appropriate or manageable. Whilst one patient described not being upset by the victim empathy work, three described experiencing an emotional effect, but felt that this was not upsetting or negative. For example: "I was sad, obviously, but not in a bad way" (P3) and "I felt bad but I expected to and it wasn't a negative thing"' (P1). 


\section{RUNNING HEAD: VICTIM EMPATHY IN AGGRESSION TREATMENT}

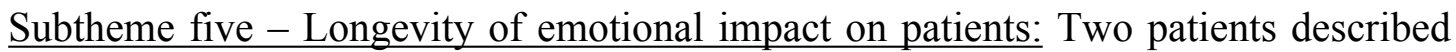
the impact of their emotional experiences to have lasted longer than the treatment session. However, a sustained, long-term impact was not clearly indicated, e.g.: "it affected me for the rest of the day and the day after" (P1).

\section{Theme four: Victim empathy content can be beneficial, with the process important}

Five facilitators and four patients described victim empathy content as largely positive. There were two subthemes:

Subtheme one - Victim empathy-content is positive: Three facilitators and four patients noted positive experiences. Facilitators, as an illustration, described observing change in patients and patients responding well to the content. For example, "When I asked the client, they felt the victim empathy aspect was important" (F2). Patients described victim empathy content positively. They outlined benefits, such as feeling pleased to have done it, to have increased their insights, to have found talking about victims helpful, and feeling listened to throughout the process; "I enjoyed the work, especially completing [victim empathy] letters" (P2), and "I benefitted from doing role plays to practice what I learned” (P3).

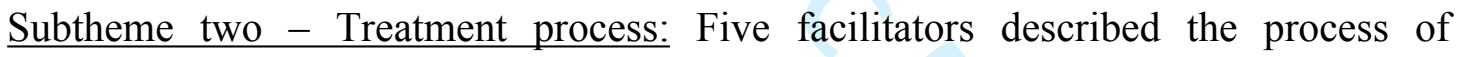
delivering victim empathy-based content. The delivery of the content using group or individual methods was considered important. For example, group treatment was considered helpful by one facilitator: "group work can be helpful as it be challenging and encourage debate from other group members" (F1). Three facilitators described individual treatment to be more able to engage patients and manage any potential impact the content could have on group processes, e.g.: "Clients respond more in individual treatment...it allows them to get involved more" (F1). 


\section{RUNNING HEAD: VICTIM EMPATHY IN AGGRESSION TREATMENT}

\section{Treatment Facilitator only theme}

\section{Theme five - Victim empathy content can help understand risk}

Three facilitators described victim empathy content as an important aspect of violence risk reduction, noting "you couldn't meet the [risk reduction] aims without it” (F7). They felt that it was helpful to address future violence risk. However, one facilitator felt that victim empathy content was also a useful way of assessing a patient's future violence risk, "even if you aren't getting feedback from the client, the information is good for [an] assessment of risk" (F6).

\section{Patient only theme}

\section{Theme Six - Patients experience of treatment begins before attending sessions}

This comprises two subthemes, as follows.

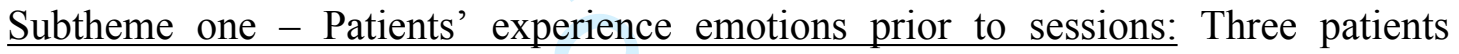
described emotional experiences that were activated before completing victim empathy content, which increased their apprehension and anxiety. For example, one patient stated: "you need to be careful about what you say... I thought what if I say something that could be taken the wrong way" (P1).

$\underline{\text { Subtheme two - Patients have prior expectations for victim empathy-based treatment: }}$ Three patients described unfounded expectations for victim empathy content before engaging, connected to their victims and the process, e.g.: "I thought my personal victims would come up and be analysed" (P2), and "I expected to do some work but also that we would go through it as quickly as we can" (P4).

\section{Discussion}

Findings indicate that facilitators and patients have some similar experiences of victim empathy-based content, sharing four themes; 1) Victim empathy content facilitates change, 2) Victim empathy content can be difficult for patients, 3) Victim empathy content can lead to 


\section{RUNNING HEAD: VICTIM EMPATHY IN AGGRESSION TREATMENT}

an emotional response and 4) Victim empathy content can be beneficial, with the process important. Overall, victim empathy-based content was perceived positively, as it was considered a useful addition to violence treatment, helping build skills and knowledge, along with contributing to an expected reduction in future violence risk. Patients experienced emotional responses during treatment, though this was not always perceived as distressing. In addition, patients did report negative emotions, such as anger, sadness and apprehension. However, this was perceived by most participants as appropriate and not distressing, with some patients reporting this as helpful for their re-evaluation of their offending and/or specific victims.

Patients felt able to learn skills conducive to empathy, such as perspective taking, through victim empathy content. This corresponds with existing literature that suggests cognitive elements of empathy are an effortful skill, requiring active participation by an individual (Day et al., 2010). This may provide some support for the Model of the Empathic Process (MEP; Barnett \& Mann, 2016), whereby patients in the current research demonstrated both affective and cognitive elements of empathy, which were developed through the completion of victim empathy treatment. As perspective taking is related to empathy and offending (Barnett \& Mann, 2013; Martinez et al., 2014), it is positive that this was reportedly impacted on by the treatment. It may also support the use of specific methods to increase offenders' perspective taking (Seinfeld et al., 2018).

Emotional responses were evidenced as resulting from both delivering and receiving victim empathy-based treatment. This was consistent with previous research (Elias \& HajYahia, 2019; Zosky, 2018). It is certainly not unexpected for those with an offence history to experience negative emotions relating to their offending (Jackson et al., 2011; Tangney et al., 2011). Shame, for example, may impact ones' self-identity, which may make empathy basedcontent particularly salient (Pinto-Gouveia \& Matos, 2011). Nevertheless, the concept of 


\section{RUNNING HEAD: VICTIM EMPATHY IN AGGRESSION TREATMENT}

empathy involves a range of responses, including affective, cognitive and physiological components (Cuff et al., 2016; Jolliffe \& Farrington, 2006). As such, some affective response by patients in this study may be a natural response to their offending, rather than distress that is caused by the specific intervention methods employed.

Patients also described negative experiences when completing victim empathy content, including experiencing distress and having existing difficulties in the skills required to meaningfully engage in treatment. These appeared to begin before attending sessions, impacted by their (unfounded) understanding and expectations of the treatment. Given the association between perspective taking and violence, initial deficits in skills conducive to empathy are certainly expected (Barnett \& Mann, 2013; Elsegood \& Duff, 2010; Seidel et al., 2013). However, it was also clear that distressing emotions, in response to considering patients' own offending or victims is important (Crisford et al., 2008; Gray et al., 2003; Zosky, 2018), as this may represent a barrier for their meaningful engagement and internalised motivation for change (Burrowes \& Needs, 2009, Ward \& Gannon, 2006). Offending can be highly stigmatised. It can therefore be challenging to an offenders' selfidentity (Cubellis et al., 2019; Evans \& Cubellis, 2015; Tewksbury, 2012), which is likely to have changed since their offending behaviour occurred, given their engagement in offendingbehaviour treatment. Reflecting on their past offence(s) may challenge their current selfidentity and cause distress, such as anger or anxiety.

\section{Limitations}

There are limitations to the current research that need to be accounted for. While the interviews were informed by a systematic literature review, no standardised or validated measures were used to capture emotional responding. Therefore, it is possible only to understand the subjective experiences and thoughts of participants. In addition, causal relationships between victim empathy-based content and participant's experiences cannot be 


\section{RUNNING HEAD: VICTIM EMPATHY IN AGGRESSION TREATMENT}

determined, which limits the extent to which victim empathy content can be understood as a causal factor for any emerging emotional experiences. Furthermore, the participants that were included in the research, including facilitators and patients, all completed/facilitated a specific offender program. Although this programme employed victim empathy material, which was consistent with other offence-focused programmes, the findings of the interview study cannot necessarily be generalised to other offender programs.

Importantly, there could be a suggestion from the systematic review that empathy intervention could impact on intermediate variables relevant to offending, such as attitudes and empathy, assessed over the short term. However, we are unable to offer evidence in relation to the longer-term impact, including re-offending. The issue of method can also not be avoided, namely the fact that the empathy content was largely embedded within broader treatment programmes. Although we focused on a single programme, with attention to the victim empathy content, it is certainly the case that the impact of the empathy component could be influenced by the content that preceded it. Nevertheless, the current qualitative approach is not seeking to offer definitive conclusions, but rather to outline emerging themes and aid directions for further enquiry. Such future enquiry may explore the adoption of more experimental/quasi-experimental approaches to consider the impact of empathy. It could also explore the appropriateness of empathy-based approaches for all offenders, accounting for offence type (i.e. sexual and/or violent offenders), including those who may present with characteristics that suggest a 'classic' empathy approach may have some challenges in application (e.g. those with clinical psychopathy, those with developmental disorders).

\section{Implications}

Despite the noted limitations, the findings have some potential clinical implications for delivering victim empathy content with offending populations. Since it was indicated that some patients had existing deficits in the skills required for victim empathy work, facilitators 
could evaluate individual ability to complete the treatment prior to engagement and provide appropriate support. Indeed, the potential impact of victim empathy content needs to be evaluated before sessions are engaged in, accounting for client expectations and treatment readiness. This may include ensuring clients are provided with accurate information about victim empathy work and offered support throughout. Facilitators should be aware of the potential distress that clients may experience when completing victim empathy content and ensure appropriate support is provided, including post sessions, with this reviewed regularly.

\section{Implications for practice}

- Definitive conclusions cannot yet be drawn in relation to the emotional impact of victim empathy work on those with an offence history. Equally, assumptions of harm cannot yet be made. There needs to be recognition that some clients view empathy work positively.

- Consideration should be given to whether group or individual empathy delivery is fitting to a particular client, accounting for their wider characteristics and individual needs, prior to the intervention commencing.

- Interventions that incorporate victim empathy work can have benefit and promote change; focus could be directed to exploring who they can be applied to and how.

\section{References}

(*Papers included in the systematic review)

Archer, J., \& Haigh, A. (1999). Sex differences in beliefs about aggression: Opponent's sex and the form of aggression. British Journal of Social Psychology, 38(1), 71-84. 


\section{RUNNING HEAD: VICTIM EMPATHY IN AGGRESSION TREATMENT}

\section{https://doi.org/10.1348/014466699164040}

*Bairn, C., Allam, J., Eames, T., Dunford, S., \& Hunt, S. (1999). The use of psychodrama to enhance victim empathy in sex offenders: an evaluation. Journal of sexual aggression, 4(1), 4-14. https://doi.org/10.1080/13552609908413278

Barnett, G. D., \& Mann, R. E. (2016). Theories of empathy deficits in sexual offenders. The Wiley Handbook on the Theories, Assessment and Treatment of Sexual Offending, 223244. https://doi.org/10.1002/9781118574003.wattso011

Barnett, G., \& Mann, R. E. (2013). Empathy deficits and sexual offending: A model of obstacles to empathy. Aggression and violent behavior, 18(2), 228-239.

https://doi.org/10.1016/j.avb.2012.11.010

Bock, E. M., \& Hosser, D. (2014). Empathy as a predictor of recidivism among young adult offenders. Psychology, Crime \& Law, 20(2), 101-115. https://doi.org/10.1080/1068316X.2012.749472

Braun, V., \& Clarke, V. (2012). Thematic analysis. In H. Cooper, P. M. Camic, D. L. Long, A. T. Panter, D. Rindskopf, \& K. J. Sher (Eds.), APA handbooks in psychology ${ }^{\circledR} . A P A$ handbook of research methods in psychology, Vol. 2. Research designs: Quantitative, qualitative, neuropsychological, and biological (p. 57-71). American Psychological Association. https://doi.org/10.1037/13620-004

Burrowes, N., \& Needs, A. (2009). Time to contemplate change? A framework for assessing readiness to change with offenders. Aggression and Violent Behavior, 14(1), 39-49. https://doi.org/10.1016/j.avb.2008.08.003

Carich, M. S., Metzger, C. K., Baig, M. S., \& Harper, J. J. (2004). Enhancing victim empathy for sex offenders. Journal of Child Sexual Abuse, 12(3-4), 255-276.

https://doi.org/10.1300/J070v12n03 10 


\section{RUNNING HEAD: VICTIM EMPATHY IN AGGRESSION TREATMENT}

*Colton, M., Roberts, S., \& Vanstone, M. (2009). Child sexual abusers' views on treatment: A study of convicted and imprisoned adult male offenders. Journal of Child Sexual Abuse, 18(3), 320-338. https://doi.org/10.1080/10538710902918170

Crisford, H., Dare, H., \& Evangeli, M. (2008). Offence-related posttraumatic stress disorder (PTSD) symptomatology and guilt in mentally disordered violent and sexual offenders. The Journal of Forensic Psychiatry \& Psychology, 19(1), 86-107. https://doi.org/10.1080/14789940701596673

Cubellis, M. A., Evans, D. N., \& Fera, A. G. (2019). Sex offender stigma: An exploration of vigilantism against sex offenders. Deviant Behavior, 40(2), 225-239. https://doi.org/10.1080/01639625.2017.1420459

Cuff, B. M., Brown, S. J., Taylor, L., \& Howat, D. J. (2016). Empathy: A review of the concept. Emotion Review, 8(2), 144-153. https://doi.org/10.1177/1754073914558466

*Day, A. (1999). Sexual offender views about treatment: A client survey. Journal of Child Sexual Abuse, 8(2), 93-103. https://doi.org/10.1300/J070v08n02 06

*Day, A., Casey, S., \& Gerace, A. (2010). Interventions to improve empathy awareness in sexual and violent offenders: Conceptual, empirical, and clinical issues. Aggression and Violent Behavior, 15(3), 201-208. https://doi.org/10.1016/j.avb.2009.12.003

*Diehl, C., Glaser, T., \& Bohner, G. (2014). Face the consequences: Learning about victim's suffering reduces sexual harassment myth acceptance and men's likelihood to sexually harass. Aggressive Behavior, 40(6), 489-503.

https://doi.org/10.1002/ab.21553

Elias, H., \& Haj-Yahia, M. M. (2019). On the lived experience of sex offenders' therapists: Their perceptions of intrapersonal and interpersonal consequences and patterns of coping. Journal of interpersonal violence, 34(4), 848-872. 


\section{RUNNING HEAD: VICTIM EMPATHY IN AGGRESSION TREATMENT}

\section{https://doi.org/10.1177/0886260516646090}

Elsegood, K. J., \& Duff, S. C. (2010). Theory of mind in men who have sexually offended against children: A UK comparison study between child sex offenders and nonoffender controls. Sexual Abuse, 22(1), 112-131. https://doi.org/10.1177/1079063209359926

Evans, D. N., \& Cubellis, M. A. (2015). Coping with stigma: How registered sex offenders manage their public identities. American Journal of Criminal Justice, 40(3), 593-619. https://doi.org/10.1007/s12103-014-9277-z

*Foubert, J. D. (2000). The longitudinal effects of a rape-prevention program on fraternity men's attitudes, behavioral intent, and behavior. Journal of American College Health, 48(4), 158-163. https://doi.org/10.1080/07448480009595691

*Garrett, T., Oliver, C., Wilcox, D. T., \& Middleton, D. (2003). Who cares? The views of sexual offenders about the group treatment they receive. Sexual Abuse: A Journal of Research and Treatment, 15(4), 323-338. https://doi.org/10.1177/107906320301500408

Geiger, B., \& Fischer, M. (2005). Naming oneself criminal: Gender difference in offenders' identity negotiation. International Journal of Offender Therapy and Comparative Criminology, 49(2), 194-209. https://doi.org/10.1177/0306624X04270552

Gillespie, S. M., Rotshtein, P., Satherley, R. M., Beech, A. R., \& Mitchell, I. J. (2015). Emotional expression recognition and attribution bias among sexual and violent offenders: a signal detection analysis. Frontiers in psychology, 6, 595. https://doi.org/10.3389/fpsyg.2015.00595

Gray, N. S., Carman, N. G., Rogers, P., MacCulloch, M. J., Hayward, P., \& Snowden, R. J. (2003). Post-traumatic stress disorder caused in mentally disordered offenders by the committing of a serious violent or sexual offence. The Journal of Forensic Psychiatry \& 


\section{RUNNING HEAD: VICTIM EMPATHY IN AGGRESSION TREATMENT}

Psychology, 14(1), 27-43. https://doi.org/10.1080/1478994031000074289

Hanson, R. K. (2003). Empathy deficits of sexual offenders: A conceptual model. Journal of Sexual Aggression, 9(1), 13-23. https://doi.org/10.1080/1355260031000137931

Hoaken, P. N., Allaby, D. B., \& Earle, J. (2007). Executive cognitive functioning and the recognition of facial expressions of emotion in incarcerated violent offenders, non-violent offenders, and controls. Aggressive Behavior: Official Journal of the International Society for Research on Aggression, 33(5), 412-421.

\section{https://doi.org/10.1002/ab.20194}

Ireland, J. L., Ireland, C. A., Morris-King, S., Turner, P., Graham-Kevan, N., Xuereb, S., \& Ireland, J. L. (2009). Life Minus Violence-Enhanced Psychological Services.

Jackson, A. L., Blackburn, A. G., Tobolowsky, P., \& Baer, D. (2011). An Examination of Guilt, Shame, Empathy and Blaming Among a Sample of Incarcerated Male and Female Offenders. Southwest Journal of Criminal Justice, 8(1).

Jolliffe, D., \& Farrington, D. P. (2004). Empathy and offending: A systematic review and meta-analysis. Aggression and violent behavior, 9(5), 441-476.

https://doi.org/10.1016/j.avb.2003.03.001

Jolliffe, D., \& Farrington, D. P. (2006). Development and validation of the Basic Empathy Scale. Journal of adolescence, 29(4), 589-611.

\section{https://doi.org/10.1016/j.adolescence.2005.08.010}

Kadambi, M. A., \& Truscott, D. (2003). Vicarious traumatization and burnout among therapists working with sex offenders. Traumatology, 9(4), 216-230.

\section{https://doi.org/10.1177/153476560300900404}

*Klepfisz, G., O'Brien, K., \& Daffern, M. (2014). Violent offenders' within-treatment change in anger, criminal attitudes, and violence risk: Associations with violent recidivism. 


\section{RUNNING HEAD: VICTIM EMPATHY IN AGGRESSION TREATMENT}

International Journal of Forensic Mental Health, 13(4), 348-362.

https://doi.org/10.1080/14999013.2014.951107

*Levenson, J. S., Macgowan, M. J., Morin, J. W., \& Cotter, L. P. (2009). Perceptions of sex offenders about treatment: Satisfaction and engagement in group therapy. Sexual Abuse, 21(1), 35-56. https://doi.org/10.1177/1079063208326072

*Levenson, J. S., Prescott, D. S., \& D'Amora, D. A. (2010). Sex offender treatment: Consumer satisfaction and engagement in therapy. International Journal of Offender Therapy and Comparative Criminology, 54(3), 307-326.

\section{https://doi.org/10.1177/0306624X08328752}

Levenson, J. S., Prescott, D. S., \& Jumper, S. (2014). A consumer satisfaction survey of civilly committed sex offenders in Illinois. International journal of offender therapy and comparative criminology, 58(4), 474-495. https://doi.org/10.1177/0306624X12472956

Mann, R. E., \& Barnett, G. D. (2013). Victim empathy intervention with sexual offenders: Rehabilitation, punishment, or correctional quackery?. Sexual Abuse, 25(3), 282-301. https://doi.org/10.1177/1079063212455669

Marshall, W. L., Hudson, S. M., Jones, R., \& Fernandez, Y. M. (1995). Empathy in sex offenders. Clinical psychology review, 15(2), 99-113. https://doi.org/10.1016/0272$\underline{7358(95) 00002-7}$

*Marshall, W. L., O'Sullivan, C., \& Fernandez, Y. M. (1996). The enhancement of victim empathy among incarcerated child molesters. Legal and Criminological Psychology, 1(1), 95-102. https://doi.org/10.1111/j.2044-8333.1996.tb00309.x

Martinez, A. G., Stuewig, J., \& Tangney, J. P. (2014). Can perspective-taking reduce crime? Examining a pathway through empathic-concern and guilt-proneness. Personality and Social Psychology Bulletin, 40(12), 1659-1667. 


\section{RUNNING HEAD: VICTIM EMPATHY IN AGGRESSION TREATMENT}

\section{https://doi.org/10.1177/0146167214554915}

Moore, K. E., Milam, K. C., Folk, J. B., \& Tangney, J. P. (2018). Self-stigma among criminal offenders: Risk and protective factors. Stigma and health, 3(3), 241.

\section{https://doi.org/10.1037/sah0000092}

Moulden, H. M., \& Firestone, P. (2007). Vicarious traumatization: The impact on therapists who work with sexual offenders. Trauma, Violence, \& Abuse, 8(1), 67-83.

\section{https://doi.org/10.1177/1524838006297729}

*Murphy, G., Powell, S., Guzman, A. M., \& Hays, S. J. (2007). Cognitive-behavioural treatment for men with intellectual disabilities and sexually abusive behaviour: a pilot study. Journal of Intellectual Disability Research, 51(11), 902-912. https://doi.org/10.1111/j.1365-2788.2007.00990.x

Newheiser, A. K., \& Barreto, M. (2014). Hidden costs of hiding stigma: Ironic interpersonal consequences of concealing a stigmatized identity in social interactions. Journal of Experimental Social Psychology, 52, 58-70. https://doi.org/10.1016/j.jesp.2014.01.002

*O'Donohue, W., Yeater, E. A., \& Fanetti, M. (2003). Rape prevention with college males: The roles of rape myth acceptance, victim empathy, and outcome expectancies. Journal of Interpersonal Violence, 18(5), 513-531.

https://doi.org/10.1177/0886260503251070

Pinto-Gouveia, J., \& Matos, M. (2011). Can shame memories become a key to identity? The centrality of shame memories predicts psychopathology. Applied Cognitive Psychology, 25(2), 281-290. https://doi.org/10.1002/acp.1689

*Pithers, W. D. (1994). Process evaluation of a group therapy component designed to enhance sex offenders' empathy for sexual abuse survivors. Behaviour Research and Therapy, 32(5), 565-570. https://doi.org/10.1016/0005-7967(94)90146-5 


\section{RUNNING HEAD: VICTIM EMPATHY IN AGGRESSION TREATMENT}

Polaschek, D. L., Calvert, S. W., \& Gannon, T. A. (2009). Linking violent thinking: Implicit theory-based research with violent offenders. Journal of interpersonal violence, 24(1), 7596. https://doi.org/10.1177/0886260508315781

Preston, S. D. (2007). A perception-action model for empathy. Empathy in mental illness, 1, 428-447. https://doi.org/10.1017/CBO9780511543753.024

Quinn, D. M., \& Chaudoir, S. R. (2009). Living with a concealable stigmatized identity: the impact of anticipated stigma, centrality, salience, and cultural stigma on psychological distress and health. Journal of personality and social psychology, 97(4), 634.

\section{https://doi.org/10.1037/a0015815}

Quinn, D. M., \& Earnshaw, V. A. (2013). Concealable stigmatized identities and psychological well-being. Social and personality psychology compass, 7(1), 40-51.

\section{https://doi.org/10.1111/spc3.12005}

Robinson, L., Spencer, M. D., Thomson, L. D., Sprengelmeyer, R., Owens, D. G., Stanfield, A. C., ... \& Johnstone, E. C. (2012). Facial emotion recognition in Scottish prisoners. International journal of law and psychiatry, 35(1), 57-61.

\section{https://doi.org/10.1016/j.ijlp.2011.11.009}

*Schewe, P. A., \& O'Donohue, W. (1993). Sexual abuse prevention with high-risk males: The roles of victim empathy and rape myths. Violence and Victims, 8(4), 339-351. https://doi.org/10.1891/0886-6708.8.4.339

*Schewe, P. A., \& O'Donohue, W. (1996). Rape prevention with high-risk males: Short-term outcome of two interventions. Archives of Sexual Behavior, 25(5), 455-471. https://doi.org/10.1007/BF02437542

Seidel, E. M., Pfabigan, D. M., Keckeis, K., Wucherer, A. M., Jahn, T., Lamm, C., \& Derntl, B. (2013). Empathic competencies in violent offenders. Psychiatry research, 210(3), 


\section{RUNNING HEAD: VICTIM EMPATHY IN AGGRESSION TREATMENT}

\section{8-1175. https://doi.org/10.1016/j.psychres.2013.08.027}

Seinfeld, S., Arroyo-Palacios, J., Iruretagoyena, G., Hortensius, R., Zapata, L. E., Borland, D., \& Sanchez-Vives, M. V. (2018). Offenders become the victim in virtual reality: impact of changing perspective in domestic violence. Scientific reports, 8(1), 1-11. https://doi.org/10.1038/s41598-018-19987-7

Shelby, R. A., Stoddart, R. M., \& Taylor, K. L. (2001). Factors contributing to levels of burnout among sex offender treatment providers. Journal of Interpersonal Violence, 16(11), 1205-1217. https://doi.org/10.1177/088626001016011006

*Stephens, K. A., \& George, W. H. (2009). Rape prevention with college men: Evaluating risk status. Journal of Interpersonal Violence, 24(6), 996-1013. https://doi.org/10.1177/0886260508319366

Tajfel, H. E. (1978). Differentiation between social groups: Studies in the social psychology of intergroup relations. Academic Press.

Tajfel, H., \& Forgas, J. P. (2000). Social categorization: Cognitions, values and groups.

Tangney, J. P., Stuewig, J., \& Hafez, L. (2011). Shame, guilt, and remorse: Implications for offender populations. Journal of Forensic Psychiatry \& Psychology, 22(5), 706-723. https://doi.org/10.1080/14789949.2011.617541

Tewksbury, R. (2012). Stigmatization of sex offenders. Deviant Behavior, 33(8), 606-623. https://doi.org/10.1080/01639625.2011.636690

Turner, J. C., Brown, R. J., \& Tajfel, H. (1979). Social comparison and group interest in ingroup favouritism. European journal of social psychology, 9(2), 187-204.

\section{https://doi.org/10.1002/ejsp.2420090207}

Van Langen, M. A., Wissink, I. B., Van Vugt, E. S., Van der Stouwe, T., \& Stams, G. J. J. M. (2014). The relation between empathy and offending: A meta-analysis. Aggression and 


\section{RUNNING HEAD: VICTIM EMPATHY IN AGGRESSION TREATMENT}

Violent Behavior, 19(2), 179-189. https://doi.org/10.1016/j.avb.2014.02.003

*Wakeling, H., Beech, A. R., \& Freemantle, N. (2013). Investigating treatment change and its relationship to recidivism in a sample of 3773 sex offenders in the UK. Psychology, Crime \& Law, 19(3), 233-252.

https://doi.org/10.1080/1068316X.2011.626413

Ward, T \& Mann. R. (2004) "Good lives and the rehabilitation of offenders: A positive approach to sex offender treatment." Positive psychology in practice: 598-616.

\section{https://doi.org/10.1002/9780470939338.ch36}

Ward, T. (2002). Good lives and the rehabilitation of offenders: Promises and problems. Aggression and Violent Behavior, 7(5), 513-528. https://doi.org/10.1016/S1359-1789(01)00076-3

Ward, T., \& Gannon, T. A. (2006). Rehabilitation, etiology, and self-regulation: The comprehensive good lives model of treatment for sexual offenders. Aggression and violent behavior, 11(1), 77-94.

https://doi.org/10.1016/j.avb.2005.06.001

*Webster, S. D., Bowers, L. E., Mann, R. E., \& Marshall, W. L. (2005). Developing empathy in sexual offenders: The value of offence re-enactments. Sexual Abuse: A Journal of Research and Treatment, 17(1), 63-77. https://doi.org/10.1177/107906320501700107

West, M. L., Vayshenker, B., Rotter, M., \& Yanos, P. T. (2015). The influence of mental illness and criminality self-stigmas and racial self-concept on outcomes in a forensic psychiatric sample. Psychiatric Rehabilitation Journal, 38(2), 150.

https://doi.org/10.1037/prj0000133

Woodyatt, L., \& Wenzel, M. (2014). A needs-based perspective on self-forgiveness: 


\section{RUNNING HEAD: VICTIM EMPATHY IN AGGRESSION TREATMENT}

Addressing threat to moral identity as a means of encouraging interpersonal and intrapersonal restoration. Journal of Experimental Social Psychology, 50, 125-135. https://doi.org/10.1016/j.jesp.2013.09.012

*Zosky, D. (2018). "Walking in her shoes": The impact of victim impact panels on perpetrators of intimate partner violence. Victims \& Offenders, 13(6), 739-756. https://doi.org/10.1080/15564886.2018.1468370 